\title{
SOKERIMAISSIN VILJELYSTÄ SEKÄ SITÄ HAITTAAVISTA TEKIJÖISTÄ
}

\author{
J. E. HÅRDH \\ Maatalouskoelaitoksen kasvitautiosasto, Tikkurila
}

Saapunut 10.6. 1955 .

Sokerimaissi on Yhdysvalloissa sekä paikoin Etelä-Euroopassa nykyisin tärkeä viljelykasvi, jolla on merkitystä sekä ruokataloudessa että rehukasvina. Sen tähkät, jotka sokeripitoisuutensa vuoksi ovat ravitsevia ja maukkaita, korjataan maitotuleentumisasteella ja käytetään joko heti vihannesten tapaan taikka säilötään. Kun sokerimaissin viljely on viime aikoina yleistynyt myös pohjoisemmissa maissa, kuten Kanadassa, jossa jo on jalostettu sikäläisiin olosuhteisiin sopivia maissilajikkeitakin, ryhdyttiin Maatalouskoelaitoksen kasvitautiosaston toimesta v. 1953 kokeilemaan aikaisten kanadalaisten lajikkeiden viljelyä meidän oloissamme.

Maassamme on aikaisemminkin suoritettu viljelykokeita sokerimaissilla mm. Maatalouskoelaitoksen puutarhaosaston toimesta sekä yksityisissä puutarhoissa; pääasiassa on tällöin kokeiltu joko englantilaisia taikka siemenkaupoista saatavissa olevia amerikkalaisia lajikkeita.

\section{Maalaji ja lannoitus}

Maissia voidaan FERGusonin (2) mukaan viljellä multavilla, kevyillä hieta- ja savimailla. Myös jäykässä maassa maissi menestyy, mikäli kylvömuokkaus siinä suoritetaan aikaisin keväällä maan lämpenemisen edistämiseksi. Sopivin maan happamuus maissille on $\mathrm{pH}$ 6.5-7.0. Tikkurilassa vuosina 1953-1954 suoritetuissa kokeissa oli osa koekenttää rinteessä, jossa maalaji on hietamultamaata, toinen osa hiesusavimaassa. Kumpaankin koekentän osaan kylvettiin samoja lajikkeita niiden maalajivaatimusten selvittämiseksi. Ilmeni, että maissi menestyi hiesusavessa heikosti arvattavasti maan hitaan lämpenemisen sekä kesän sateista johtuvan kuorettumisen vuoksi. Mainittakoon, että myös McKILlican (7) pitää maan kuorettumista maissille haitallisena, sen orastumista sekä juurien toimintaa häiritsevänä tekijänä. Vuonna 1954 kokeiltiin sokerimaissin viljelyä jäykässä hietasavessa eräällä 
Taulukko 1. Tulokset sokerimaissin lajikekokeista Tikkurilassa v. 1953 ja 1954. Ruudun koko $3 \mathrm{~m}^{2}$, kolme kerrannaista. Kylvö 20. 5, korjuu v. 195327.8 ja 7. 9, v. 1954 10. 9 ja 21. 9.

Table 1. Sweet corn variety tests at Tikkurila in 1953 and 1954. Test plot $3 \mathrm{~m}^{2}$, three replicates. Planting 20. 5, havvest in 1953 27. 8 and 7. 9, in 195410.9 and 21. 9.

\begin{tabular}{|c|c|c|c|c|c|c|}
\hline \multirow{3}{*}{$\begin{array}{l}\text { Lajike } \\
\text { Variety }\end{array}$} & \multicolumn{3}{|c|}{1953} & \multicolumn{3}{|c|}{1954} \\
\hline & $\begin{array}{c}\text { Kylvö } \\
\text { orastu- } \\
\text { miseen } \\
\text { Days } \\
\text { plan }\end{array}$ & $\begin{array}{l}\text { stä pv } \\
\text { tähki- } \\
\text { miseen } \\
\text { from } \\
\text { ting }\end{array}$ & $\begin{array}{l}\text { Sato } \mathrm{kg} / \mathrm{a} \\
\text { Yield } \mathrm{kg} / \mathrm{a}\end{array}$ & $\begin{array}{c}\text { Kylvö } \\
\text { orastu- } \\
\text { miseen } \\
\text { Days } \\
\text { plan }\end{array}$ & $\begin{array}{l}\text { östä pv } \\
\text { tähki- } \\
\text { miseen } \\
\text { from } \\
\text { nting }\end{array}$ & $\begin{array}{l}\text { Sato } \mathrm{kg} / \mathrm{a} \\
\text { Yield } \mathrm{kg} / \mathrm{a}\end{array}$ \\
\hline & $\begin{array}{c}\text { to } \\
\text { tillering }\end{array}$ & $\begin{array}{c}\text { to } \\
\text { tasseling }\end{array}$ & & $\begin{array}{c}\text { to } \\
\text { tillering }\end{array}$ & $\begin{array}{c}\text { to } \\
\text { tasseling }\end{array}$ & \\
\hline Early Alberta $\quad \ldots \ldots \ldots \ldots \ldots \ldots$ & 16 & 48 & 62.2 & 9 & 53 & 45.2 \\
\hline Seneca $60 \quad \ldots \ldots \ldots \ldots \ldots \ldots \ldots$ & 17 & 57 & 48.4 & 9 & 62 & 39.5 \\
\hline Squaw Corn $\quad \ldots \ldots \ldots \ldots \ldots \ldots$ & 18 & 48 & 43.1 & 10 & 54 & 27.7 \\
\hline Altagold $\ldots \ldots \ldots \ldots \ldots \ldots \ldots \ldots$ & 17 & 57 & 38.0 & 11 & 61 & 39.0 \\
\hline Banting $\ldots \ldots \ldots \ldots \ldots \ldots \ldots \ldots \ldots \ldots$ & 17 & 57 & 27.7 & 10 & 59 & 31.0 \\
\hline Pickaninny $\ldots \ldots \ldots \ldots \ldots \ldots \ldots$ & 19 & 60 & 24.2 & 11 & 62 & 15.2 \\
\hline Earliest Pioneer $\quad \ldots \ldots \ldots \ldots \ldots$ & 19 & 59 & 22.4 & 11 & 66 & 26.7 \\
\hline Orchard Baby $\quad \ldots \ldots \ldots \ldots \ldots \ldots$ & 19 & 62 & 22.0 & 12 & 65 & 32.2 \\
\hline Dorinny $\ldots \ldots \ldots \ldots \ldots \ldots \ldots \ldots$ & 18 & 59 & 16.0 & 11 & 69 & 10.3 \\
\hline
\end{tabular}

tilalla Etelä-Hämeessä (Katisten kartano, Hämeenlinna). Tällöin sokerimaissi orastui ja kehittyi heikosti, mistä oli seurauksena harva kasvusto sekä sadossa runsaasti lovitähkäisyyttä. Näinollen lienee sopivin maalaji sokerimaissille oloissamme kevyt, multava hieta- tai savimaa.

Sokerimaissi vaatii runsaan lannoituksen. Kirjallisuudessa esitettyjen tietojen mukaisesti (2) annettiin maissille kumpanakin koevuonna $70 \mathrm{t}$ karjanlantaa, $700 \mathrm{~kg}$ Y-lannoitetta (sis. $7 \% \mathrm{~N}, 6.5 \% \mathrm{P}_{2} \mathrm{O}_{5}, 18.5 \% \mathrm{~K}_{2} \mathrm{O}$ ) ja 100 kg kotkafosfaattia hehtaaria kohden. Lannoituksen tärkeys kävi ilmi rinnakkaiskokeessa Tikkurilassa v. 1953, jolloin toinen koe samoilla sokerimaissilajikkeilla sijaitsi viljakasvilannoituksen saaneella maalla $\left(735 \mathrm{~kg}\right.$ /ha PK-lannoitetta, sis. $20.5 \% \mathrm{P}_{2} \mathrm{O}_{5}$ ja $18.5 \% \mathrm{~K}_{2} \mathrm{O}$ sekä $300 \mathrm{~kg}$ /ha Nks.). Kasvusto jäi näin lannoitetussa maassa normaalia matalammaksi ja tähkiminen tapahtui myöhemmin, kuin runsaan lannoituksen saaneessa kokeessa. Lisäksi olivat kasvit kauttaaltaan punertavia, mikä viittaa fosforin puutteeseen maassa.

Maissi kylvettiin vuosina 1953 ja 1954 suoraan avomaalle toukokuun 20 päivänä 1 metrin rivivälein ja $10 \mathrm{~cm}: n$ etäisyyksin. Taimivälit riveissä harvennettiin myöhemmin $30 \mathrm{~cm}: n$ suuruisiksi. Rikkaruohot poistettiin kitkemällä, rivivälit harattiin kahdesti ja samalla mullattiin rivit kasvien tukemiseksi sekä juurien kasvun edistämiseksi.

\section{Laiikkeet}

Kumpanakin koevuonna suoritettiin kaksi korjuuta. Sokerimaissin korjuun oikea ajankohta, tähkien maitotuleentumisaste, todetaan luottien väristä, joka täl- 
löin muuttuu tumman ruskeaksi, miltei mustaksi. Korjattaessa poistettiin tähkistä suojuslehdet ja tähkät punnittiin heti korjuun tapahduttua (taul. 1). Ensimmäinen ankara hallayö, joka turmeli maissin lehdet, sattui vuonna 19537 p. syyskuuta ja v. 195424 p. syyskuuta.

Early Alberta oli v. 1953 kokeilluista sokerimaissilajikkeista satoisin ja aikaisin. Kovamaissilajike Squaw Corn oli yhtä aikainen tähkimiseen nähden, mutta sen satoisuus oli Early Albertaa heikompi. Vuonna 1954 oli satoero Early Albertan sekä sitä lähinnä olevien Seneca 60:n ja Altagoldin kesken pienempi; Early Albertan tähkiminen tapahtui tällöin kokeilluista lajikkeista ensimmäisenä. Esitetyt tulokset perustuvat kahden vuoden kokeisiin, joten ne ovat vain suuntaa-antavia eri lajikkeiden viljelyarvoa oloissamme arvosteltaessa. Ilmeistä on kuitenkin, että kasvukauden ollessa normaali sokerimaissin viljelyä voidaan meillä harrastaa ja että aikaiset lajikkeet ehtivät meillä valmistua korjuuasteelle.

Kylvösiemenen tuottaminen nykyisin tunnetuista hybridimaisseista, jollaisia kokeissa oli mukana Seneca 60 sekä Earliest Pioneer, ei maassamme ole mahdollista. Sen toteamiseksi, voidaanko pysyvien lajikkeiden siementä saada maassamme luontaisen pölytyksen tietä, kerättiin edellä selostetuista kokeista tähkiä, joiden annettiin huoneenlämmössä tuleentua ja kuivua ilmakuiviksi. Sen jälkeen määritettıin siementen itävyys ja orastuminen. Eri lajikkeista saatujen siementen itävyys oli 82.0 $99.5 \%$ ja orastuminen $69.0-95.5 \%$. Korkein itävyys- ja orastumis- $\%$ oli aikaisilla Early Alberta- ja Squaw Corn-lajikkeilla, mikä ilmeisesti johtui tähkien pitemmälle ehtineestä kyspymisestä niitä korjattaessa.

\section{Sokerimaississa todetuista kasvitaudeista}

Edellä mainittiin sokerimaissilla todettuina f y s i o g e e n is in ä t a u t e in a fosforin puutteesta johtuva kasvin punertuminen sekä maan kylmyydestä johtuva heikko kasvu, mistä voi olla seurauksena lovitähkäisyyttä. Hallanvauriot ovat maissin kasvulle usein ratkaisevia, koska tämä kasvi kuuluu hallanarimpiin viljelykasveihin. Vuonna 1954 todettiin kuitenkin, että oraalla oleva sokerimaissi kestää lyhytaikaista pakkastakin. Sanottuna vuonna oli Tikkurilassa 1.6 vastaisena yönä maanpinnassa 2 tunnin ajan $-3^{\circ} \mathrm{C}$ ja samoin $3.6-0.5^{\circ} \mathrm{C}$; silloin oli sokerimaissi jo taimella. Pakkanen aiheutti lehtien punertumista, mikä kuitenkin pian hävisi, jonka jälkeen kasvit kehittyivät normaalisti.

Si e n i t a u d e is t a, joita tähänastisissa sokerimaissikokeissa Tikkurilassa on todettu, ovat siemenen itämistä estävät taudit tärkeitä. Dicksonin (1) mukaan tapahtuu maissin itäminen hitaasti, ja sienet turmelevat helposti siemenen, jos maan lämpötila on alle $12^{\circ} \mathrm{C}$. Maissin siemenessä kulkeutuvien sienien tutkimiseksi lajiteltiin vuonna 1954 saatu Early Alberta-lajikkeen siemensato surkastumisasteen perusteella kolmeen ryhmään: 1. täysimittaiset, pinnaltaan sileät jyvät, 2. hieman kurttuiset ja 3. sangen pienikokoiset ja ryppyiset jyvät. Kuhunkin ryhmään kuuluvia jyviä idätettiin $4 \times 50 \mathrm{kpl}$. steriloidussa hiekassa tavanomaisia idätysastioita käyttäen. Jyvien itävyys sekä tärkeimpien sienisukujen paljous jyvissä määritettiin 


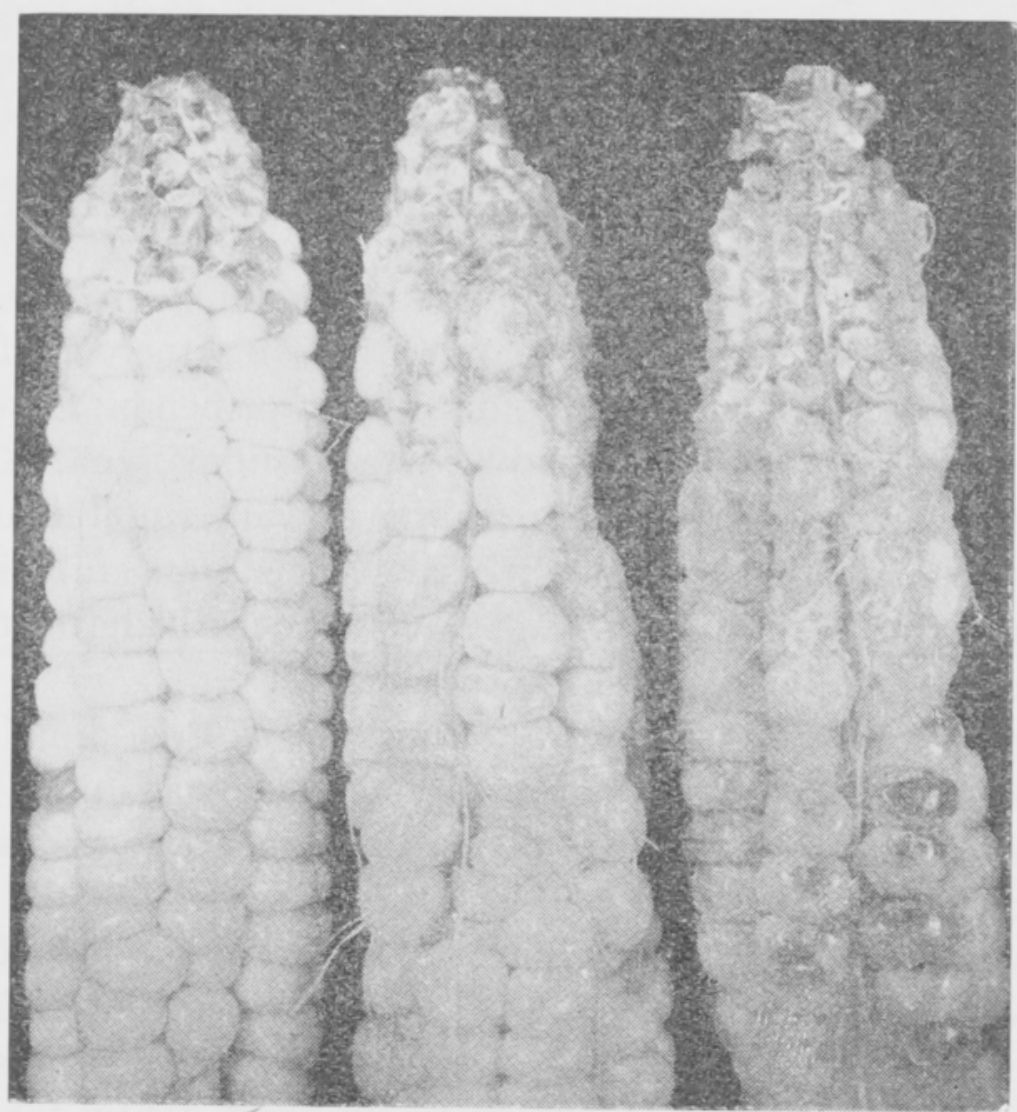

Kuva 1. Botrytis cinerean (vas.) ja Fusarium sambucinumin (kesk. ja oik.) aiheuttama tähkän mätäneminen. Orig.

Figure 1. Ear rotting caused by Botrytis cinerea (left) and Fusarium sambucinum (center and right). Orig.

(taul. 2). Rypistyneiden jyvien (2. ja 3. ryhmä) itävyys oli selostetussa kokeessa sangen huono, ja sienten runsaus näissä huomattava. Tärkeimmät itämistä ehkäisevät sienet kuuluivat ilmeisesti Botrytis- ja Hormodendrum-sukuihin. Kirjallisuudessa mainitaan maissin siemenen mukana kulkeutuvina, itämistä haittaavina sieninä näiden lisäksi Aspergillus-, Fusarium-, Mucor- ja Penicillium-lajeja $(6,10)$. Myös Fusarium-sukuun kuuluvat maasienet voivat olla syynä siemenen huonoon itämiseen. Niinpä Hon (3) suorittamassa tutkimuksessa todettiin Gibberella saubinetii (Fusarium graminearum) maassa eläväksi Fusarium-lajiksi, joka voi esiintyä maissilla primaarisena patogeenina. Pratrin, Leibyn ja Chuppin (9) mukaan voidaan siementen sienituhoja vähentää peittaamalla, ja tähän suositellaan TMTD-pitoisia aineita (esim. Arasania).

Tähkän osittainen tai täydellinen mä tä n e m i n e n on kirjallisuuden mukaan yleinen haitta maissin viljelyssä (1). Sitä voivat aiheuttaa bakteerit sekä monet sienilajit, joista $\mathrm{mm}$. Fusarium graminearum ja $F$. moniliforme ovat yleisiä $(8,11)$. Vuonna 1954 esiintyi sokerimaissikokeessa Tikkurilassa sateisesta kesästä johtuen runsaasti tähkän mätänemistä (kuva 1). Turmeltuneita tähkiä näytti eri lajikkeissa olevan yhtä paljon. Viallisista tähkistä eristettiin seuraavat sienilajit: 
Taulukko 2. Sokerimaissin jyväsadon itävyys, homeisuus ja tärkeimpien sienisukujen runsaus siinä v. 1954. Lajike Early Alberta.

Table 2. Germination and moldiness of the sweet corn kernels, and percentage of the most important fungi in 1954. Variety Early Alberta.

\begin{tabular}{cccccccc}
\hline $\begin{array}{c}\text { Kurttuisuus } \\
\text { Shrivelling }\end{array}$ & $\begin{array}{c}\text { Itävyys } \\
\text { Germination } \\
\%\end{array}$ & $\begin{array}{c}\text { Homeisuus } \\
\text { Moldiness } \\
\%\end{array}$ & $\begin{array}{c}\text { Botrytis } \\
\%\end{array}$ & $\begin{array}{c}\text { Fusarium } \\
\%\end{array}$ & $\begin{array}{c}\text { Hormoden- } \\
\text { drum } \\
\%\end{array}$ & $\begin{array}{c}\text { Mucor } \\
\%\end{array}$ & $\begin{array}{c}\text { Penicillium } \\
\%\end{array}$ \\
\hline 1. & 99.5 & 15.0 & 0 & 0.5 & 5.0 & 0 & 9.5 \\
2. & 29.5 & 100.0 & 15.5 & 27.0 & 76.5 & 1.5 & 1.0 \\
3. & 1.0 & 100.0 & 38.0 & 5.0 & 79.0 & 5.5 & 5.5
\end{tabular}

Botrytis cinerea Pers., Fusarium anguioides Sherb., F. graminearum Schw. ja F. sambucinum FUck. Mainitut Fusarium-lajit ovat Suomessa jo ennestäär tunnettuja (5), josta syystä niitä ei tässä lähemmin tarkastella. Botrytis cinerea sekä Fusarium sambucinum eristettiin useista tähkistä, minkä vuoksi oli ajateltavissa, että niillä olisi merkitystä tähkien mätänemistä aiheuttavina sieninä. Niillä suoritettiin siitä syystä infektiokoe.

Inokulointia varten viljeltiin Banting-lajikkeesta eristettyä $F$. sambucinumia sekä Early Alberta -lajikkeesta saatua B. cinereaa koeputkissa kaura-agarilla. Kun kumpikin sieni oli muodostanut pahkoja, valittiin koeruuduilta 30 aikaisella maitotuleentumisasteella olevaa Seneca 60 -lajikkeen tähkää, ja nämä numeroitiin. Seneca 60 oli kokeeseen sopivin lajike, koska siinä inokuloinnin tapahtuessa oli runsaimmin nuoria emitähkiä. Mainituista 30 tähkästä inokuloitiin $10 \mathrm{kpl}$. F. sambucinumilla, $10 \mathrm{~B}$. cinerealla ja 10 oli inokuloimattomia tähkiä.

Inokulointi tapahtui 23. 9. 1954 seuraavasti. Tähkiä irroittamatta raotettiin niiden suojuslehtiä niin, että tähkän latvaosa paljastui. Tähän asetettiin jyvänaiheiden väliin steriloidulla neulalla koeputkesta $1-2$ pahkaa, jonka jälkeen suojuslehdet suljettiin ja inokulointikohdan ympärille pantiin kumirengas, joka tiivisti sen. Inokuloimattomien tähkien suojuslehdet avattiin ja suljettiin samalla tavalla. Ensimmäisten syyshallojen jälkeen pantiin kaikki tähkät suojuslehtiä poistamatta kosteaan kammioon huoneenlämpöön (lämpötila $18^{\circ} \mathrm{C}$, ilman suht. kosteus $100 \%$ ). Tähkät olivat kosteassa kammiossa 4. 10--11. 10. 54, eli 7 vuorokautta, jonka jälkeen ne analysoitiin.

Taulukko 3. Infektiokoe $B$. cinerealla ja $F$. sambucinumilla.

Table 3. Infection test with B. cinerea and F. sambucinum.

\begin{tabular}{lccc}
$\begin{array}{l}\text { Inokulointı } \\
\text { Inoculation }\end{array}$ & $\begin{array}{c}\text { Terveitä } \\
\text { tähkiä } \\
\text { Uninfected } \\
\text { ears }\end{array}$ & $\begin{array}{c}\text { Tähkän kärki } \\
\text { mädäntynyt } \\
\text { Ear tip rotted }\end{array}$ & $\begin{array}{c}\text { Koko tähkä } \\
\text { turmeltunut } \\
\text { Entive ear } \\
\text { rotted }\end{array}$ \\
\hline Kontrolli - Check $\ldots$ & 5 & 3 & 2 \\
B. cinerea ......... & 1 & 9 & 0 \\
F. sambucinum ...... & 0 & 8 & 2
\end{tabular}


Inokuloiduista tähkistä eristettiin analysoinnin jälkeen samat sienilajit kuin ne, joilla tähkät oli inokuloitu. Koe osoittaa, että Botrytis cinerea, yleinen harmaahomeen aiheuttaja sekä $F$. sambucinum saattavat aiheuttaa maissin tähkän mätänemistä, jos lämpö- ja kosteussuhteet ovat saastuntaan rähden edulliset.

\section{Tuhoeläimet}

Tikkurilassa suoritetuissa kokeissa on tähän mennessä todettu seuraavia tuhoeäimiä sokerimaissin turmelijoina.

Juurimadot (Agriotes sp.) voivat nakertaa nuorten taimien juurenniskaa ja varrentyveä sekä aiheuttaa siten kasvin kuihtumisen. Pitemmälle ehtineissä kasveissa juurimatojen tuhot ilmenevät heikkona kasvuna sekä usein kasvin punertumisena.

Kahukärpänen (Oscinis frit L.) on todettu oloissamme sangen haitalliseksi maissin tuholaiseksi. Sen toukka tunkeutuu varren ytimeen ja turmelee sen sekä aiheuttaa pääverson surkastumisen. Tällöin muodostuu kasviin useita sivuversoja, jotka heikon kasvun vuoksi eivät jaksa eivätkä ehdi muodostaa tähkiä. Usein näissä sivuversoissakin on todettu kahukärpäsen toukkia.

Ripsiäisiä esiintyy sokerimaississa lämpimänä ja kuivana aikana runsaasti, jolloin ne vioittavat sekä varsilehtiä että tähkien suojuslehtiä. Nämä muuttuvat kellertäviksi, keltajuovaisiksi sekä rypistyvät ja repeilevät myöhemmin. Sään muuttuessa koleaksi ja sateiseksi ripsiäiset vähenevät huomattavasti. Syyskuussa 1954 määritettiin sokerimaissista kerättyjä ripsiäislajeja1 ${ }^{1}$. Näistä oli suurin osa, n. 85 \% kauraripsiäisiä Frankliniella tenuicornis UzEL, joita esiintyi-vielä lokakuussa maissintähkien suojuslehtien välissä. Muutamia ruohoripsiäis (Anaphothrips obscurus f. hemimacroptera PR.) -yksilöitä esiintyi niinikään tähkissä.

\section{Yhteenveto}

Sokerimaissin viljelyä selvittävissä kokeissa Tikkurilassa v. 1953 ja 1954 osoittautui Early Alberta kokeilluista lajikkeista satoisimmaksi. Se on oloihimme ilmeisesti myös riittävän aikainen.

Sokerimaissin kylvö suoraan avomaalle on meillä edullisin toimittaa silloin, kun maan lämpötila kylvösyvyydessä on vähintään $12^{\circ} \mathrm{C}$. Karjanlanta sekä fosfaattilannoitteet edistävät kasvin nopeata alkukehitystä. Kasvukauden aikana on syytä hävittää rikkaruohot sekä harata maa kaksi kertaa. Lämpimänä kesänä voidaan sokerimaissista saada maassamme kelvollista siementä.

Tärkeimmät tähän mennessä maassamme todetut sokerimaissin kasvitaudit ovat fosforin puutteesta johtuva kasvin punertuminen, hallanviat, tuhosienien aiheuttama heikko itävyys sekä tähkän mätäneminen. Viimeksi mainitun aiheutta-

$\left.{ }^{1}\right)$ Määritykset suoritti maat. ja metsät. kand. KATRI TIITtAnen, josta lausun hänelle parhaat kiitokset. 
jina voivat olla Botrytis cinerea PERs. ja Fusarium sambucimum Fuck. Lisäksi eristettiin turmeltuneista tähkistä $F$. anguioides SHERB. sekä F. graminearum ScHw.

Sokerimaissin tuholaisiksi on maassamme todettu juurimadot (Agriotes sp.), kahukärpänen (Oscinis frit L.), kauraripsiäinen (Frankliniella tenuicornis UzEL) sekä ruohoripsiäinen (Anaphothrips obscurus f. hemimacroptera PR.).

\section{KIRJALLISUUTTA}

(1) Dickson, J. G. 1947. Diseases of field crops, p. 1-429. New York.

(2) Ferguson, W. 1948. Vegetable growing. Canada Dept. of Agriculture. Publication 816, p. 1-55.

(3) Ho, W. 1944. Soil-inhabiting fungi attacking the roots of maize. Iova State Agr. Exp. Sta., Res. Bull. 332 , p. $401-446$.

(4) Hảrdh, J. E. 1954. Sokerimaissilajikkeista Suomessa. Puutarha 5, p. $246-247$.

(5) Jamalainen, E. A. 1955. Fusarium species causing plant diseases in Finland. Acta Agralia Fennica 83 , p. $159-172$.

(6) Johann, H., Holbert, J. R. \& Dickson, J. G. 1931. Further studies on Penicillium injury to corn. Jour. Agr. Res. 43, p. $757-790$.

(7) McKillican, W. C. 1929. Corn growing in Manitoba. Canada Dept. of Agric. Bull. 121, p. 1-15.

(8) Pearson, N. L. 1931. Parasitism of Gibberella saubinetii on corn seedlings. Jour. Agr. Res. 43, p. $569-596$

(9) Pratt, A. J., Leiby, R. W. \& Chupp, Ch. 1950. The vegetable garden. Cornell Ext. Bull. 696, p. $1-64$.

(10) Semeniuk, G. 1942. Molds in stored corn and their control. Rept. Agr. Res. Iova Corn Res. Inst. 7 , p. $57-59$.

(11) VoorheEs, R. K. 1935. Histological studies of a seedling disease of corn caused by Gibberella moniliformis. Jour. Agr. Res. 49, p. 1009-1015.

\section{SUMMARY:}

\section{ON GROWING SWEET CORN AND ON FACTORS HAMPERING IT}

J. E. HẢrdH

Agricultural Research Centre, Department of Plant Pathology, Tikkurila

In 1953 and 1954 experiments were made to test the possibilities of raising sweet corn in Finland. Nine sweet corn varieties, obtained from the Central Experimental Farm, Ottawa, Canada, were examined. Both years the Early Alberta variety proved to be the earliest and the best yielding of the varieties examined (table 1).

The best soil types were light humous loam and clayey mould, heavy clay, on the contrary, being unsuitable for sweet corn because of its higher moisture and lower temperature in the early summer.

Sweet corn was given an abundant fertilization, 70 tons manure, $700 \mathrm{~kg}$ Y-fertilizer (contains $7 \%$ $\left.\mathrm{N}, 6.5 \% \mathrm{P}_{2} \mathrm{O}_{5}, 18.5 \% \mathrm{~K}_{2} \mathrm{O}\right)$ and $100 \mathrm{~kg}$ Kotka-phosphate $\left(25 \% \mathrm{P}_{2} \mathrm{O}_{5}\right)$ pro hectare. The sowing date was in each case May 20th, the seeds were planted by hand in rows 1 meter apart. The plants were spaced at a distance of $30 \mathrm{~cm}$, hoeing being done twice each season. In 1953 there was killing frost on the 
7 th of September, in 1954 on the 24 th of September. The germinability of the corn kernels, dried up in room temperature, was good, 82.0-99.5\%, the best germination occurring in the Early Alberta and Squaw Corn varieties.

\section{Diseases of sweet corn}

The reddish color of the leaves on young plants was due to the temperature falling below zero during two nights in June, 1954. The growth of the plants was normal, however, and no frost-killing occurred. Reddish leaves may be caused by phosphorus deficiency, too.

In the germination tests of the sweet corn seed, obtained from the test plots, the germination of shrivelled grains was poor, and they were frequently moldy (table 2). The most important growth-inhibiting fungi belonged apparently to the genera Botrytis and Hormodendrum.

In 1954 the rotting of ears was due to persistent rainy weather. The following fungi were isolated from the rotted ear tips (figure 1): Botrytis cinerea PERs., Fusarium anguioides SHERB., F. graminearum ScHw. and F. sambucinum FUCK. Botrytis cinerea and Fusarium sambucinum seemed to be of importance, and an inoculation test was performed by those fungi. The species tested seem to be able to cause the rotting of ears when the conditions for infection are suitable.

\section{Insect pests}

The following insect pests were established on sweet corn in 1953 and 1954: wireworms (Agriotes sp.), frit-fly (Oscinis frit L.) and two species of thripses (Frankliniella tenuicornis UzEL and Anaphothrips obscurus f. hemimacroptera PR.). 